\section{Intima-media complex in the investigation of atherosclerosis in HIV-infected patients}

Mr. Editor,

The authors of the article "Assessment of intima-media complex in carotid, femoral and right subclavian arteries for early investigation of atherosclerosis in HIV-infected patients"(1), published in the Nov/Dec 2013 issue of this journal, compared the measurements of common carotid, femoral and right subclavian arteries of HIV-infected patients with a control group utilizing manual and automatic sonographic measurement methods. Based on the observed values of measurements, they have concluded that HIV-infected individuals did not present increased risk for atherosclerosis as compared with individuals in the control group. Studies published in the specialized literature that evaluated the risk for atherosclerosis in both HIV-negative and HIV-positive patients do not utilize the simple intima-media complex measurement for diagnosis of vascular disease. Therefore, the authors' assertion that either normal or altered measurements in both groups, using manual or automatic method, does not rule out the presence of atherosclerosis must be viewed with caution. The sensitivity of such method is very low as it considers only the measurement of the vascular wall. Usually the artery only shows decreased caliber at advanced phases of atherosclerosis. Several studies in the literature have reported a process of atherosclerosis in HIV-positive individuals with consequential coronary artery disease ${ }^{(2)}$. The investigation of endothelial dysfunction in brachial and carotid arteries with apparently normal parietal measurements has revealed a significantly decreased response of the flow-mediated dilatation compared to HIV-negative individuals ${ }^{(3)}$. In a study reported from Brazil by Andrade et al. ${ }^{(4)}$, the authors observed that such endothelial dysfunction is only revealed with a response to induced ischemia. The base values of the brachial artery diameter are similar in HIVnegative individuals but significantly different from HIV-positive individuals, particularly for those undergoing antiretroviral therapy. Similar findings were reported with the investigation of carotid and brachial arteries by other authors ${ }^{(5-7)}$. So, the conclusion that can be drawn from the study published by Godoi et al. ${ }^{(\mathbf{1})}$ in this journal is that the simple parietal measurement for early identification of atherosclerotic vascular disease is not useful either in HIV-positive or in HIV-negative individuals. The differences observed between manual and automatic measurements have no repercussion of the technique sensitivity.

\section{References}

1. Godoi ETAM, Brandt CT, Godoi JTAM, et al. Avaliação do complexo médiointimal nas artérias carótidas, femorais e subclávia direita para investigação precoce de aterosclerose em pacientes infectados pelo HIV. Radiol Bras. 2013;46:333-40.

2. DAD Study Group, Friis-Moller N, Reiss P, et al. Class of antiretroviral drugs and the risk of myocardial infarction. N Engl J Med. 2007;356:1723-35.

3. Longenecker CT, Hoit BD. Imaging atherosclerosis in HIV: carotid intima-media thickness and beyond. Transl Res. 2012;159:127-39.

4. Andrade AC, Ladeia AM, Netto EM, et al. Cross-sectional study of endothelia function in HIV-infected patients in Brazil. AIDS Res Hum Retroviruses. 2008;24:27-33.

5. Cotter BR, Torriani FJ. Cardiovascular effects of antiretroviral therapy and noninvasive assessments of cardiovascular disease in HIV infection. Cardiovasc Toxicol. 2004;4:281.

6. Blanco JJ, García IS, Cerezo JG, et al. Endothelial function in HIV-infected patients with low or mild cardiovascular risk. J Antimicrob Chemother. 2006;58:1339.

7. Stein JH. Endothelial function in patients with HIV infection. Clin Infect Dis. 2006;43:540-1.

Cesar Augusto de Araújo Neto ${ }^{1}$, Ana Cristina Oliveira Andrade ${ }^{2}$, Roberto Badaró

1. PhD, Professor, Department of Medicine and Diagnosis Support, Faculdade de Medicina da Bahia - Universidade Federal da Bahia (UFBA), Salvador, BA, Brazil.

2. Associate Professor, Escola Bahiana de Medicina e Saúde Pública, Salvador, BA, Brazil.

3. Private Docent, Professor, Department of Medicine and Diagnosis Support, Faculdade de Medicina da Bahia - Universidade Federal da Bahia (UFBA), Salvador, BA, Brazil.

Reply

The interpretation of results was appropriate as the information presented by the article is considered, but the intima-media complex measurement by Doppler ultrasonography, in spite of being technically simple and easily performed, and particularly for being noninvasive, plays a relevant role in the screening for systemic atherosclerosis. It is important to observe that the study population was young (aged up to 50 years), exactly to avoid the bias of age. Additionally, the authors have managed to include only patients undergoing antiretroviral therapy for at least five years, which corresponds to at least five years of disease. It is our intention to repeat such measurements in the future, as a cohort study follow-up, since it is possible that the earlier atherosclerosis in HIV-positive patients takes more time to be detected in the population free of infection.

\section{Emmanuelle Tenório Albuquerque Madruga Godoi}

$\mathrm{PhD}$, Associate Professor, Department of Medical Practice, Universidade Federal de Pernambuco (UFPE), Recife, PE, Brazil. 